\title{
Adaptif Range-Constrained Otsu Untuk Pemilihan Threshold Secara Otomatis Pada Histogram Citra Dengan Variansi Kelas Yang Tidak Seimbang
}

\author{
Gama Wisnu Fajarianto', Ahmad Hifdhul Abror², Nur Hayatin ${ }^{3}$ \\ ${ }^{1}$ Magister Teknik Informatika, Fakultas Teknologi Informasi, ITS, Surabaya \\ ${ }^{2}$ Sistem Informasi, Fakultas Saintek, UIN Sunan Ampel, Surabaya \\ ${ }^{3}$ Teknik Informatika, Fakultas Teknik, Universitas Muhammadiyah Malang \\ E-mail: ${ }^{1}$ gama.fajarianto12@mhs.if.its.ac.id, ${ }^{2}$ abror@uinsby.ac.id, ${ }^{3}$ noorhayatin@umm.ac.id
}

\begin{abstract}
Abstrak
Image Thresholding merupakan proses segmentasi untuk memisahkan foreground dan background pada citra dengan cara membagi histogram citra menjadi dua kelas. Beberapa metode thresholding seperti Otsu dan Range-constrained Otsu menggunakan nilai variansi dari histogram untuk mendapatkan titik threshold, namun ketika menangani citra yang memiliki nilai variansi kelas foreground dan background tidak seimbang titik threshold yang dihasilkan kurang tepat. Paper ini mengusulkan metode Adaptif Range-constrained Otsu untuk mengatasi permasalahan variansi kelas yang tidak seimbang dengan cara mencari kelas yang memiliki nilai variansi lebih besar, untuk mendapatkan titik threshold yang lebih tepat. Pengujian menggunakan 22 NDT image dengan evaluasi misclassification error rate dan metode perankingan menunjukkan metode ini menghasilkan rerata ME 0.1153. Sedangkan Otsu sebesar 0.1746. Nilai rerata ranking 3.55, selisih 0.05 dibanding Kittler III. Hasil ini menunjukkan metode yang diusulkan kompetitif, terutama untuk segmentasi citra yang memiliki variansi kelas tidak sama.
\end{abstract}

Kata kunci: segmentasi, thresholding, histogram, Otsu, Range-constrained.

\begin{abstract}
Image thresholding is segmentation process for separating foreground and background of an image by dividing image histogram into two classes. Several thresholding methods like Otsu and Rangeconstrained Otsu using the variance value of the histogram to get the threshold point, but when handling images that have unbalance class variance of the foreground and background produce less accurate threshold point. This paper proposes a method Adaptive Range-constrained Otsu to solve unbalance class variance problem by finding a class that has greater variance value to obtain more accurate threshold point. NDT testing using 22 images with misclassification error rate evaluation and ranking methods shows that this method results ME average of 0.1153, while Otsu method results 0.1746 . The rankings mean value is 3.55 , which has the difference of 0.05 when compared with Kittler III. These results show that the proposed method is competitive, especially for image segmentation with different class variance.
\end{abstract}

Key word: segmentasi, thresholding, histogram, Otsu, Range-constrained.

\section{Pendahuluan}

Segmentasi citra dengan metode thresholding menjadi efektif digunakan untuk membedakan objek dengan background jika nilai keabuan menjadi pembeda yang penting diantara keduanya (Xu, Xu, Jin, \& Song, 2011). Thresholding Otsu Method (OM) merupakan metode thresholding yang paling populer digunakan. Berbagai penerapan pada aplikasi dengan menggunakan OM, seperti segmentasi untuk mendapatkan objek ikan (Yao, Duan, Li, \& Wang, 2013) mammogram (Liu, Tsai, Liu, Yu, \& Yu, 2012) dan juga aplikasi modifikasi Otsu untuk segmentasi aurora (Gao, et al., 2011).

OM bekerja dengan baik ketika digunakan pada citra dengan variansi kelas yang kurang lebih sama, namun akan bias jika digunakan pada citra dengan variansi kelas yang berbeda. Sehingga, OM cenderung akan memotong kelas yang lebih besar (Qiao, Hu, Qian, Luo, \& Nowinski, 2007). OM juga memiliki karakteristik unik, yaitu sama dengan rerata nilai mean dari dua kelas yang dibagi dengan hasil threshold itu sendiri. Padahal titik perpotongan dari distribusi objek dan background adalah threshold yang ideal sebagai nilai pemisah antara objek dengan background (Xu, Xu, Jin, \& Song, 2011).

Untuk mengatasi kelemahan OM yang memiliki kecenderungan bias, dikembangkan Rangeconstrained Otsu Method (ROM) (Xu, Xu, Jin, \& Song, 2011). Ide dari metode ini adalah membatasi

6| Register: Jurnal Ilmiah Teknologi Sistem Informasi, Januari 2016, Volume 2, Nomor 1 
rentang pencarian thresholding Otsu. Hasil eksperimen yang dilakukan menunjukkan bahwa algoritma ROM superior dibandingkan OM dan beberapa metode yang lain. Namun, algoritma ini memiliki kekurangan, yaitu selalu membatasi pencarian pada area piksel yang lebih gelap dari titik threshold Otsu. Sehingga metode ROM hanya sesuai untuk menangani citra yang memiliki variansi kelas lebih besar dibagian piksel terang.

Paper ini mengusulkan sebuah metode Adaptif Range-constrained Otsu untuk segmentasi citra dengan variansi kelas yang tidak seimbang dan mampu beradaptasi terhadap segala perbedaan variansi kelas pada citra. Sehingga ketika dilakukan proses thresholding dapat menghasilkan titik intersection point yang lebih tepat pada lembah gray-level histogram.

\section{Metode Penelitian}

Pada paper ini diusulkan sebuah metode Adaptif Range-constrained Otsu untuk segmentasi citra keabuan dengan variansi kelas yang tidak seimbang. Metode ini akan mendeteksi secara otomatis variansi kelas yang lebih besar. Sehingga bias dari metode Otsu dapat diketahui. Proses selanjutnya dilakukan thresholding untuk menghasilkan titik intersection point yang lebih tepat.

Ide dari metode Adaptif Range-constrained Otsu adalah mencari lembah terdekat dari hasil thresholding Otsu yang dilakukan pada citra dengan histogram keabuan $[1 \ldots L]$. Dimana, $L$ adalah nilai maksimal tingkat keabuan piksel pada citra. Langkah pertama yang dilakukan metode ini adalah melakukan thresholding Otsu pada keseluruhan piksel citra (Otsu, 1979) hingga diperoleh threshold T1. Kemudian, threshold Otsu digunakan kembali dengan rentang histogram 1 hingga $T_{l}$ untuk mencari $T_{L}$ (Threshold Left) dan dilakukan proses yang sama untuk mendapatkan $T_{R}$ (Threshold Right) dengan rentang $T_{l}$ hingga $L$. Persamaan 1 dan 2 digunakan untuk mencari nilai $T_{L}$ dan $T_{R}$.

$$
\begin{aligned}
& T_{L}=\underset{1 \leq T<T_{1}}{\arg \max }\left\{\sigma_{b}^{2}(T)\right\} \\
& T_{R}=\underset{T_{1} \leq T<L}{\arg \max }\left\{\sigma_{b}^{2}(T)\right\}
\end{aligned}
$$

Banyaknya nilai piksel pada setiap bagian histogram dinotasikan dengan $N_{L}$ dan $N_{R}$ sesuai persamaan 3 dan 4.

$$
\begin{aligned}
& N_{L}=\sum_{i=T_{L}}^{T_{1}} 1 \\
& N_{R}=\sum_{i=T_{1}+1}^{T_{R}} 1
\end{aligned}
$$

Langkah selanjutnya adalah mencari variansi terbesar dari histogram dengan cara membandingkan nilai rerata piksel antara $T_{L}$ hingga $T_{1}$ dan $T_{1}$ hingga $T_{R}$ ditunjukkan pada Gambar 1e. Rerata banyaknya piksel dinotasikan dengan $\mu_{L} \operatorname{dan} \mu_{R}$ sesuai persamaan 5 dan 6.

$$
\begin{aligned}
& \mu_{L}=\sum_{i=T_{L}}^{T_{1}} \frac{n_{i}}{N_{L}} \\
& \mu_{R}=\sum_{i=T_{1}+1}^{T_{R}} \frac{n_{i}}{N_{R}}
\end{aligned}
$$

Kemudian menentukan batasan rentang $a$ dan buntuk mencari threshold optimal $T_{2}$ sesuai persamaan 7 dan 8 .

$$
\begin{aligned}
& a=\left\{\begin{array}{c}
1, \text { jika } \mu_{L} \leq \mu_{R} \\
T_{1}+1, \text { ika } \mu_{L}>\mu_{R}
\end{array}\right. \\
& b=\left\{\begin{array}{c}
T_{1}, \text { jika } \mu_{L} \leq \mu_{R} \\
L, \text { jika } \mu_{L}>\mu_{R}
\end{array}\right.
\end{aligned}
$$

Langkah terakhir adalah menghitung threshold Optimal $T_{2}$ dengan persamaan 9.

$T_{2}=\underset{a \leq T<b}{\arg \max }\left\{\sigma_{b}^{2}(T)\right\}$ 
Hasil eksperimen Gambar 1 (c). menunjukkan bahwa ROM tidak dapat melakukan segmentasi dengan baik ditunjukkan dengan adanya beberapa objek citra yang terhapus. Berbeda dengan penerapan Adaptif Range-constrained Otsu yang bisa memilih secara otomatis area dengan variansi yang lebih besar, ketika rentang pencarian threshold optimum $\left(T_{2}\right)$ dilakukan pada bagian histogramdengan rentang $\left[T_{1}-L\right]$ maka hasilnya menjadi lebih bagus dibandingkan dengan Otsu ditunjukkan pada Gambar 1 (d).

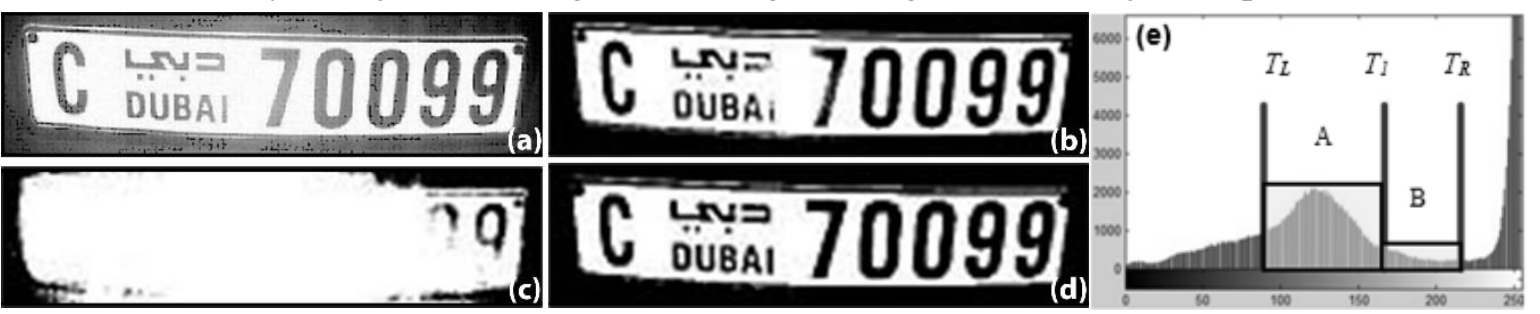

Gambar 1 (a) Citra plat nomer (Fan \& Lei, 2012), (b) Otsu menghasilkan $T_{1}=176$, (c) ROM dengan rentang [1- $\left.T_{1}\right]$ menghasilkan $T_{2}=95$ (d), ROM dengan rentang $\left[T_{1}-L\right]$ menghasilkan $T_{2}=223$, (e) histogram citra plat nomer dengan rerata tingkat keabuan area $\mathrm{A}>\mathrm{B}$

\section{Hasil Penelitian dan Pembahasan}

Penelitian ini menggunakan metode pengujian Misclassification Error-rate (ME) sebagai evaluasi performa yang akan membandingkan hasil segmentasi sebenarnya (groundtruth) dengan hasil segmentasi dari metode yang diajukan. ME akan menghitung jumlah piksel background dari hasil segmentasi yang dapat terklasifikasi dengan benar terhadap groundtruth $\left(B_{0} \cap B_{T}\right)$ dan jumlah piksel objek dari hasil segmentasi yang dapat terklasifikasi dengan benar terhadap groundtruth $\left(F_{0} \cap F_{T}\right)$. Selanjutnya, kedua nilai tersebut dijumlahkan dan hasilnya dibagi dengan jumlah total piksel ( $B_{0}+F_{0}$ ). Nilai ME ditentukan sesuai dengan persamaan 10.

$M E=1-\frac{\left|B_{0} \cap B_{T}\right|+\left|F_{0} \cap F_{T}\right|}{\left|B_{0}\right|+\left|F_{0}\right|}$

Data set NDT image digunakan untuk uji coba terhadap metode yang diusulkan. Nilai ME akan dihitung dan dilakukan perangkingan yang bertujuan untuk mengukur dan mengevaluasi performa dari metode yang diusulkan. Tabel 1 menunjukkan hasil pengukuran performa dari metode yang diusulkan dibandingkan dengan beberapa metode lain yang diambil dari hasil penelitian sebelumnya (Beauchemin, 2013).

Hasil evaluasi performa menggunakan ME menunjukkan bahwa metode yang diusulkan menghasilkan nilai rerata ME sebesar 0.1153. Sedangkan metode Otsu menghasilkan nilai rerata ME sebesar 0.1746. Untuk pengukuran performa secara perankingan, metode yang diusulkan mendapatkan nilai rerata ranking 3.55. Sedangkan metode Kittler III mendapatkan nilai rerata ranking 3.50 dan metode Otsu 3.98.

Dari 22 NDT image yang digunakan untuk uji coba, sejumlah 6 citra menghasilkan ranking 1 dengan metode yang diusulkan, citra tersebut adalah NDT image nomor 3 dengan ME sebesar 0.0021, nomor 6 dengan ME sebesar 0.0206, nomor 8 dengan ME sebesar 0.0078, nomor 13 dengan ME sebesar 0.0062 , nomor 15 dengan ME sebesar 0.0033 dan nomor 20 dengan ME sebesar 0.0189. Sedangkan 3 citra yang lain, yaitu NDT image nomor 5 menghasilkan ranking 7 dengan nilai ME sebesar 0.8854, nomor 19 menghasilkan ranking 8 dengan nilai ME sebesar0.3930 dan nomor 22 menghasilkan ranking 7 dengan nilai ME sebesar 0.1252. Gambar 2 menunjukkan beberapa contoh citra hasil segmentasi dengan beberapa metode.

Hasil segmentasi ketiga citra yang memilki nilai ME tinggi (Nomor 5, 19, 22) dikarenakan metode yang diusulkan menggunakan threshold Otsu sebagai titik awal threshold $\left(T_{1}\right)$. Sehingga ketika threshold pertama $\left(T_{1}\right)$ berada diluar dua puncak histogram objek dan background, maka mengakibatkan titik threshold kedua $\left(T_{2}\right)$ menjadi kurang optimal. Faktor lain yang menyebabkan hasil segmentasi menjadi kurang optimal adalah ketika input citra memiliki karakteristik dengan bentuk histogram unimodal. Dimana, nilai histogram objek sangat rendah sehingga titik awal threshold terlalu mengarah pada background citra. 
Dari analisa hasil pengujian tersebut dapat disimpulkan bahwa metode yang diusulkan mampu melakukan segmentasi citra lebih baik dibanding dengan hasil segmentasi metode Otsu, dengan nilai rerata ME sebesar 0.1153. Nilai rerata tersebut lebih kecil dibandingkan dengan nilai rerata Otsu. Semakin kecil nilai rerata ME, maka performa metode semakin baik. Dari hasil perankingan,metode yang diusulkan memiliki rerata ranking satu level dibawah metode Kittler III. Dengan selisih ranking sebesar 0.005. ini membuktikan bahwa metode yang diusulkan cukup kompetitif, terutama untuk segmentasi citra yang memiliki variansi kelas yang tidak sama.

Tabel 1 Perbandingan hasil evaluasi performa dengan ME

\begin{tabular}{|c|c|c|c|c|c|c|c|c|}
\hline \multirow{2}{*}{$\begin{array}{l}\text { No. } \\
\text { Citra } \\
\text { NDT }\end{array}$} & \multicolumn{8}{|c|}{ Metode [ Ranking (ME) ] } \\
\hline & Abutaleb & Otsu & Kittler-III. & Kapur et al. & Tsai & Li\& Lee & Pham & Proposed \\
\hline 1 & $5(0.0730)$ & $3(0.0630)$ & $1(0.0120)$ & $1(0.0700)$ & $7(0.2000)$ & $6(0.0900)$ & $8(0.6700)$ & $2(0.0136)$ \\
\hline 2 & $4(0.0230)$ & $7.5(0.4900)$ & $1(0.0000)$ & $3(0.0030)$ & $5(0.2400)$ & $7(0.4900)$ & $6(0.4600)$ & $2(0.0001)$ \\
\hline 3 & $5(0.3100)$ & $6(0.5300)$ & $2(0.0030)$ & $3(0.0040)$ & $4(0.1700)$ & $7(0.5500)$ & $8(0.5600)$ & $1(0.0021)$ \\
\hline 4 & $5(0.2600)$ & $6(0.3300)$ & $2(0.0210)$ & $1(0.0110)$ & $4(0.1900)$ & $7(0.3700)$ & $8(0.5100)$ & $3(0.0187)$ \\
\hline 5 & $5(0.7800)$ & $2(0.6400)$ & $8(0.9100)$ & $6(0.8500)$ & $3(0.6500)$ & $4(0.6800)$ & $1(0.5200)$ & $7(0.8854)$ \\
\hline 6 & $3(0.0230)$ & $7(0.4300)$ & $6(0.0370)$ & $4(0.0280)$ & $5(0.3500)$ & $8(0.4500)$ & $2(0.0210)$ & $1(0.0206)$ \\
\hline 7 & $8(0.1500)$ & $4(0.0200)$ & $3(0.0150)$ & $6(0.0380)$ & $7(0.1400)$ & $2(0.0140)$ & $1(0.0040)$ & $5(0.0372)$ \\
\hline 8 & $8(0.2400)$ & $5(0.1200)$ & $2(0.0280)$ & $6(0.1400)$ & $7(0.2300)$ & $4(0.1100)$ & $3(0.0520)$ & $1(0.0078)$ \\
\hline 9 & $7(0.2400)$ & $3(0.0120)$ & $1(0.0030)$ & $5(0.0470)$ & $6(0.0560)$ & $3(0.0120)$ & $3(0.0120)$ & $4(0.0350)$ \\
\hline 10 & $8(0.2400)$ & $5(0.0660)$ & $1(0.0040)$ & $7(0.1500)$ & $6(0.1400)$ & $3.5(0.0520)$ & $3.5(0.0520)$ & $2(0.0236)$ \\
\hline 11 & $8(0.2100)$ & $3(0.0290)$ & $4(0.0360)$ & $7(0.0560)$ & $5(0.0410)$ & $1(0.0110)$ & $2(0.0270)$ & $6(0.0469)$ \\
\hline 12 & $7(0.0440)$ & $2(0.0080)$ & $8(0.0510)$ & $6(0.0400)$ & $3(0.0110)$ & $4(0.0160)$ & $1(0.0020)$ & $5(0.0174)$ \\
\hline 13 & $4(0.0240)$ & $3(0.0220)$ & $2(0.0080)$ & $5(0.0360)$ & $6(0.2900)$ & $7(0.7100)$ & $8(0.7600)$ & $1(0.0062)$ \\
\hline 14 & $8(0.4800)$ & $2(0.0010)$ & $7(0.2700)$ & $6(0.0220)$ & $5(0.0110)$ & $3(0.0040)$ & $1(0.0000)$ & $4(0.0106)$ \\
\hline 15 & $5(0.0370)$ & $4(0.0290)$ & $3(0.0190)$ & $2(0.0070)$ & $8(0.0430)$ & $6(0.0370)$ & $7(0.0380)$ & $1(0.0033)$ \\
\hline 16 & $7(0.8800)$ & $4(0.4800)$ & $2(0.0070)$ & $1(0.0030)$ & $4(0.4800)$ & $4(0.4800)$ & $5(0.5800)$ & $6(0.7835)$ \\
\hline 18 & $8(0.2500)$ & $4(0.0360)$ & $2(0.0250)$ & $7(0.2200)$ & $6(0.0840)$ & $1(0.0210)$ & $5(0.0480)$ & $3(0.0267)$ \\
\hline 19 & $6(0.3200)$ & $2.5(0.1500)$ & $1(0.0540)$ & $7(0.3500)$ & $5(0.2000)$ & $4(0.1800)$ & $2.5(0.1500)$ & $8(0.3930)$ \\
\hline 20 & $7.5(0.6200)$ & $4(0.0700)$ & $3(0.0280)$ & $7.5(0.6200)$ & $6(0.2800)$ & $2(0.0200)$ & $5(0.2500)$ & $1(0.0189)$ \\
\hline 21 & $4(0.1100)$ & $7(0.3000)$ & $8(0.4700)$ & $2(0.0180)$ & $5(0.1800)$ & $6(0.2700)$ & $1(0.0010)$ & $3(0.0374)$ \\
\hline 22 & $5(0.0710)$ & $1(0.0150)$ & $3(0.0300)$ & $6(0.1200)$ & $4(0.0580)$ & $2(0.0210)$ & $8(0.1600)$ & $7(0.1252)$ \\
\hline 23 & $8(0.0990)$ & $2.5(0.0003)$ & $7(0.0750)$ & $6(0.0230)$ & $4(0.0100)$ & $1(0.0000)$ & $2.5(0.0003)$ & $5(0.0225)$ \\
\hline Rerata & $6.16(0.2493)$ & $3.98(0.1746)$ & $3.50(0.0957)$ & $4.89(0.1298)$ & $\begin{array}{r}5.23 \\
(0.1843)\end{array}$ & $\begin{array}{r}4.23 \\
(0.2085)\end{array}$ & $4.16(0.2217)$ & $\begin{array}{r}3.55 \\
(0.1153) \\
\end{array}$ \\
\hline
\end{tabular}

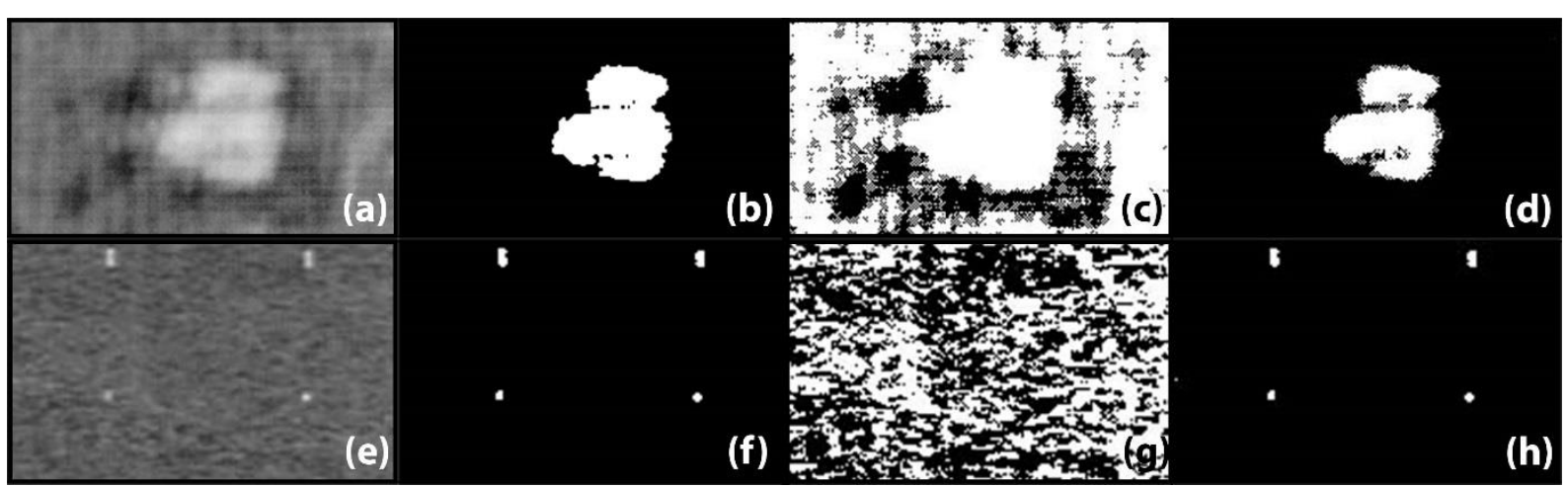

Gambar 2 Perbandingan citra hasil. (a) NDT 1, (b) groundtruth NDT1, (c) NDT 1 dengan ROM, (d) NDT 1 dengan metode yang diusulkan, (e) NDT 2, (f) groundtruth NDT2, (g) NDT 2 dengan OM, (h) NDT 2 dengan metode yang diusulkan

\section{Kesimpulan}

Pada paper ini diusulkan metode Adaptif Range-constrained Otsu yang merupakan metode perbaikan dari metode ROM untuk segmentasi citra yang memiliki variansi kelas tidak sama. Idenya adalah mencari lembah terdekat terhadap threshold hasil metode Otsu $\left(T_{1}\right)$ untuk mendapatkan threshold optimum $\left(T_{2}\right)$. Metode ini akan melakukan dua kali Thresholding Otsu. Kemudian menghitung nilai rerata masing-masing kelas. Dimana threshold optimum akan didapatkan pada area kelas yang memiliki 
nilai rerata kecil. Hasil pengujian menggunakan 22 NDT image dengan evaluasi misclassification error rate dan metode perankingan menunjukkan bahwa metode ini menghasilkan rerata ME 0.1153. Sedangkan Otsu sebesar 0.1746. Nilai rerata ranking 3.55, selisih 0.05 dibanding Kittler III. Metode yang diajukan ini memiliki keunggulan dalam hal kompleksitas seperti metode Otsu yang memiliki nilai kompleksitas rendah sehingga memiliki running time yang relatif cepat. Hasil ini menunjukkan metode yang diusulkan kompetitif terutama untuk segmentasi citra yang memiliki variansi kelas tidak sama.

Kombinasi dengan metode density clustering yang memperhatikan jarak ketetanggaan piksel dan konsentrasi nilai keabuan piksel pada histogram dapat dijadikan pengembangan lebih lanjut terhadap metode ini. Sehingga lebih baik dalam melakukan segmentasi terhadap citra yang memiliki karakteristik dengan bentuk histogram selain bimodal.

\section{Ucapan Terima Kasih}

Kami mengucapkan terima kasih kepada Dr. Agus Zainal Arifin, S.Kom, M.Kom, dosen pascasarjana Teknik Informatika Institut Teknologi Sepuluh Nopember (ITS) Surabaya, selaku dosen pembimbing dalam penelitian ini. Tidak lupa pula kami berterima kasih kepada ITS yang telah memberikan beasiswa Fresh Graduate untuk melanjutkan studi S2 di pascasarjana ITS.

\section{Referensi}

Beauchemin, M. (2013). Image Thresholding Based on Semivariance. Pattern Recognition Letters, $34(5), 456-462$.

Fan, J. L., \& Lei, B. (2012). A Modified Valley-Emphasis Method for Automatic Thresholding. Pattern Recognition Letters, 33(6), 703-708.

Gao, X., Fu, R., Li, X., Tao, D., Zhang, B., \& Yang, H. (2011). Aurora Image Segmentation by Combining Patch and Texture Thresholding. Computer Vision and Image Understanding, 115(3), 390-402.

Hou, Z., Hu, Q., \& Nowinski, W. (1732-1743). On Minimum Variance Thresholding. Pattern Recognition Letters, 27(14), 2006.

Liu, C. C., Tsai, C. Y., Liu, J., Yu, C. Y., \& Yu, S. S. (2012). A Pectoral Muscle Segmentation Algorithm for Digital Mammograms Using Otsu Thresholding and Multiple Regression Analysis. Computers \& Mathematics with Applications, 64(5), 1100-1107.

Otsu, N. (1979). Thresholds Selection Method form Grey-Level Histograms. IEEE Trans. On Systems, Man and Cybernetics, 9(1), 62-66.

Qiao, Y., Hu, Q., Qian, G., Luo, S., \& Nowinski, W. L. (2007). Thresholding Based on Variance and Intensity Contrast. Pattern Recognition, 40(2), 596-608.

Xu, X., Xu, S., Jin, L., \& Song, E. (2011). Characteristic Analysis of Otsu Threshold and Its Applications. Pattern Recognition Letters, 32(2011), 956-961.

Yao, H., Duan, Q., Li, D., \& Wang, J. (2013). An improved K-means Clustering Algorithm for Fish Image Segmentation. Mathematical and Computer Modelling, 58(3-4), 790-798. 